\title{
МОДЕЛЬ СОЦИАЛЬНО-ОБРАЗОВАТЕЛЬНОЙ ИНТЕГРАЦИИ ДЕТЕЙ С ЗАДЕРЖКОЙ ПСИХИЧЕСКОГО РАЗВИТИЯ
}

\section{MODEL OF SOCIO-EDUCATIONAL INTEGRATION OF CHILDREN WITH MENTAL DEVELOPMENT DELAY}

E. Pozhidaeva

A. Kolevatova

Summary: The article actualizes the problem of social and educational integration of children with mental retardation. The author considers this problem through modeling the processes of social and educational integration. The article reveals the basic concepts of modeling the process of social and educational integration, presents a model of social and educational integration of children with mental retardation, presents the conceptual consequences of its implementation.

Keywords: children with mental retardation, social and educational integration, model, correctional and developmental activities and support.
Пожидаева Екатерина Юрьевна

К.n.н., преподаватель, ФГБОУ ВО «Курская государственная сельскохозяйственная академия имени И.И. Иванова»

Pozhidaeva.e.yu@yandex.ru

Колеватова Анна Сергеевна

ФГБОУ ВО «Курский государственный медицинский университет» Министерства здравоохранения

Российской Федерации

Emelianova2015@mail.ru

Аннотация: В статье актуализируется проблематика социально-образовательной интеграции детей с задержкой психического развития. Автор рассматривает данную проблему через моделирование процессов социально-образовательной интеграции. В статье выявлены основные концепты моделирования процесса социально-образовательной интеграции, представлена модель социально-образовательной интеграции детей с задержкой психического развития, приведены концепт-следствия ее реализации.

Ключевые слова: дети с задержкой психического развития, социально-образовательная интеграция, модель, коррекционно-развивающая деятельность и сопровождение.

процесса систематического обучения. В связи с этим, проблема моделирования процесса социально-образовательной интеграции на основе учета факторов психопатологии, препятствующей нормальному систематическому обучению, успешной адаптации и положительной социализации, приобретает на сегодняшний день особую актуальность $[2 ; 6 ; 8 ; 9]$.

Современный уровень развития психолого-педагогической научной отрасли позволяет констатировать тот факт, что дети, имеющие любой вид отклонений от возрастной нормы развития при определенных смоделированных условиях социально-образовательной среды, могут демонстрировать прогрессивную динамику своего развития, включая также достижение удовлетворяющего уровня эмоционального благополучия и ускоренную положительную социальную адаптацию. Эта концепция оформилась благодаря научным исследованиям ученых, среди которых Е.Л. Иденбаум, В.И. Нодельман, К.С. Лебединская, И.А. Коробейников, Г.Р. Новикова, И.А. Крамаренко, В.Ф. Шалимов, В.И. Лубовский, У.В. Ульенкова и др. (Иденбаум, Нодельман, 2015; Лебединская, 1973; Коробейников, 2002; Новикова, Шалимов, Крамаренко, 2017; Лубовский, 1971; Ульенкова, 2004).

Общее мнение ученых в рамках данной концепции сходится в обосновании временности нарушений, успешность компенсации которых зависит от своевре- 
менной и систематической диагностики, а также грамотного моделирования процесса коррекции [5].

С позиций анализа и оценки нарушений познавательной деятельности детей с ЗПР, задержку психического развития признают одной из основных аномальных форм данного процесса. Специфическую особенность в этом плане имеет структура интеллектуальной недостаточности по сравнению с умственной отсталостью. В основе этих различий лежит гетеротропность нарушений различных психических функций детей, что объясняет в ряде случаев сохранность логического мышления при нарушениях процессов внимания, памяти, способности к умственной деятельности и т.д.

Также необходимо отметить и еще один важнейший аспект, который требует полноценного учета в коррекционно-сопровождающей деятельности детей с ЗПР - дети, относящиеся к данной категории достаточно активно и результативно могут принимать психолого-педагогическую помощь и продуктивно ее использовать что еще раз подтверждает необходимость предусмотрения в процессе моделирования коррекционного процесса в условиях образовательной интеграции всех возможных факторов, которые могут успешно повлиять на способность детей с ЗПР к переносу навыков умственной, интеллектуальной деятельности на иные ситуативные планы. Это говорит о том, что при соблюдении основных императивов моделирования процессов социально-образовательной интеграции дети с ЗПР становятся способными выполнять широкий спектр интеллектуальных заданий, близких к нормативному уровню [3].

В связи с вышесказанным следует выделить основные концепты моделирования процесса социально-образовательной интеграции, среди которых:

- своевременность диагностических обследований, в рамках которых учитывается этапность и наиболее раннее начало выявления у ребенка всевозможных соответствующих отклонений; данный концепт представляет собой первоочередное и необходимо условие в разработке модели социально-образовательной интеграции в целях успешной реабилитации детей с ЗПР и коррекции;

- необходимость реализации комплексного подхода к осуществлению диагностических мер: необходимо учитывать результаты различных сторон обследования (педиатрические, психоневрологические, генетические, нейрофизиологические, биохимические и многие другие); результаты медицинских исследований при этом должны обязательно сопоставляться с данными логопедических, педагогических, психологических и др. обследований; это обеспечивает результативность выявления ведущих нарушений в психическом развитии ребенка, что является важным фасилитирущим фактором в коррекционно-развивающей психолого-педагогической деятельности;

- целостность и корректность психолого-педагогической диагностики, что является важнейшим аспектом при определении уровня психического развития и зон ближайшего развития и др.

Также необходим отметить, что категория детей с ЗПР является весьма неоднородной, но, тем не менее, из основных специфических состояний отклонения выделяют такие как замедление процессов становления эмоционально-личностных характеристик, а также произвольной поведенческой регуляции, включая задержанное развитие различных сторон познавательной деятельности. Все это должно быть учтено при разработке моделей социально-образовательной интеграции детей с ЗПР.

Модель социально-образовательной интеграции для рассматриваемой категории детей должна определяться соответствием педагогической системе, в которой предметно-развивающая, образовательно-воспитывающая и материально-техническая среды максимально отвечают потребностям, возможностям и способностям детей, а также обеспечиваются психолого-педагогическим сопровождением специалистов, которые курируют развитие и адаптацию, охватывают весь спектр взаимодействия с ребенком и тем микросоциумом, в котором он социализируется.

Помимо этого, модель должна быть обеспечена стабильной организационной и дидактико-методологической поддержкой, а также поддержкой органов образования, в спектр обязанностей которой входит ответственность за уровень профессиональной компетентности тех специалистов, которые обеспечиваю реализацию модели образовательной интеграции детей с ЗПР.

Также необходимо отметить, что концепция, задачи и цели психолого-педагогического процесса сопровождения в рамках образовательной интеграции характеризуются рядом особенностей, которые также опираются на модель коррекционно-развивающей работы в условиях соответствующей образовательной среды, на основе которых в части управления модели формулируются основные принципы коррекционной деятельности, которые, в свою очередь, определяют и регулируют содержательную часть процесса сопровождения детей с ЗПР, включая учет позиции психолога в отношении различных участников образовательных отношений и пути оценивания эффективности коррекционно-развивающей сопроводительной деятельности (Рис. 1).

Таким образом, процесс реализации модели соци- 


\section{МОДЕЛЬ ОБРАЗОВАТЕЛЬНОЙ ИНТЕГРАЦИИ И КОРРЕКЦИОННО-РАЗВИВАЮЩЕЙ ДЕЯТЕЛЬНОСТИ В СОПРОВОЖДЕНИИ ДЕТЕЙ С ЗПР}

ЦЕЛЬ: соответствие педагогической системе, в которой предметно-развивающая, образовательновоспитывающая и материально-техническая среды максимально отвечают потребностям, возможностям и спо собностям детей, а также обеспечиваются психологолпедагогическим сопровождением специалистов.

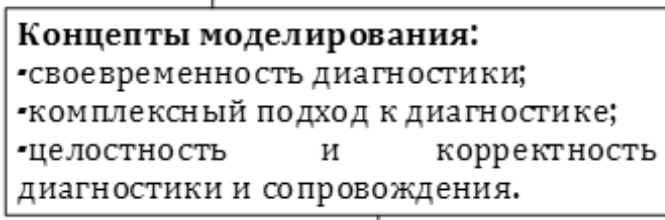

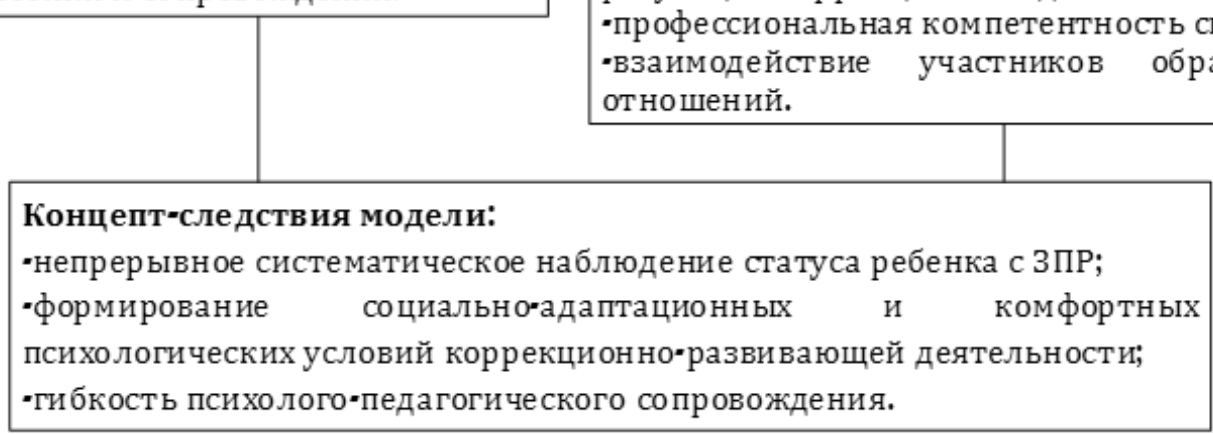

Рис. 1. Модель социально-образовательной интеграции детей с задержкой психического развития ально-образовательной интеграции детей с ЗПР удовлетворяет следующим условиям:

- непрерывность и систематическое наблюдение статуса ребенка его поступательной динамики и достижения прогрессивных изменений в рамках получения положительных образовательных результатов; решение данной задачи также подразумевает конфиденциальность хранящейся в образовательном учреждении информации о жизни, деятельности, динамике психического развития ребенка;

- ответственный подход в выборе методов медикопсихологической, психологической и педагогической диагностики; в процессе такой деятельности у наблюдающего психолога должны быть четко сформированы представления о том, на каких этапах социально- образовательной интеграции диагностическое тестирование и обследование необходимо и какими средствам оно должно быть осуществлено (необходим также учет правовых, этических аспектов в данной деятельности);

- разработка, формирование и реализация социально-адаптационных и комфортных психологических условий в рамках коррекционно-развивающей деятельности для успешного включения ребенка в интегрированное образовательное пространство;
- гибкость схем и алгоритмов открытой коррекционно-развивающей и социально-образовательной среды, учитывающих особенности психического и психологического развития детей;

- гибкость психолого-педагогического сопровождения, подразумевающая вариативность подходов в деятельности самих специалистов (педагогов, дефектологов, психологов логопедов и др.) и ориентированная на достижение поставленных целей и задач в отношении каждого отдельного ребенка.

Таким образом, считаем необходимым еще раз отметить, что результат реализации модели социально-образовательной интеграции детей с ЗПР, который должен быть обеспечен соответствующим психолого-педагогическим сопровождением, нужно рассматривать в ракурсе достижения психического здоровья ребенка, процесс обеспечения которого отражает коррекционно-развивающую деятельность на всех этапах онтогенеза. Создание на основе разработанной модели социальнопсихологических и педагогических условий в образовательной среде для каждого ребенка с 3ПР с учетом его личностных особенностей, способных обеспечить успешность его развития, является главной целью психолого-педагогического сопровождения в условиях социально-образовательной интеграции. 


\section{ЛИТЕРАТУРА}

1. Гаджимагомедова, Т.Г. Проблемы познавательной деятельности детей с ЗПР / Т.Г. Гаджимагомедова // Сибирский педагогический журнал. - 2007. - № 13. - C. 300-307.

2. Долгобородова, Д.А. Особенности обучения младших школьников с задержкой психического развития / Д.А. Долгобородова, В.А. Варенцов // Актуальные вопросы современной психологии: материалы IV Междунар. науч. конф. (г. Краснодар, февраль 2017 г.). - Краснодар: Новация, 2017. - C. $52-54$.

3. Ильмурзина, Л.М. Современные аспекты развития детей с задержкой психического развития / Л.М. Ильмурзина // Международный журнал гуманитарных и естественных наук. - 2016. - № 2. - С. 32-35.

4. Кисова, В.В. Эмпирический анализ состояния системы образования детей с задержкой психического развития в России / В. В. Кисова, А. В. Семенов // Международный журнал прикладных и фундаментальных исследований. - 2015. - № 12 (Часть 6) - С. 1127-1132.

5. Семенова, Л.Э. Психология детей с задержкой психического развития: исследования Ульяны Васильевны Ульенковой / Л.Э. Семенова, Н.П. Шашкина // Вестник Мининского университета. - 2014. - № 3 (7). - С. 31-38.

6. Судакова, Д.В. Трудности обучения детей с задержкой психического развития [Электронный ресурс] / Д.В. Судакова. - 2019. - Режим доступа: https:// infourok.ru/trudnosti-obucheniya-detey-s-zpr-3770879.html

7. Филиппова, Н.В. Современный взгляд на задержку психического развития / Н.В. Филиппова, Ю.Б. Барыльник, А.С. Исмайлова // Международный журнал прикладных и фундаментальных исследований. - 2015. - № 10 (Часть 2) - С. 256-262.

8. Шамарина, Е.В. Использование клинико-педагогических исследований в коррекции познавательной деятельности младших школьников с задержкой психического развития / Е.В. Шамарина // Известия Тульского государственного университета. Гуманитарные науки. - 2015. - № 1. - С. 104-114.

9. Шамарина, Е.В. Проблемы дифференциальной диагностики и коррекции речи младших школьников с задержкой психического развития / Е.В. Шамарина // Ученые записки Орловского государственного университета. Серия: Гуманитарные и социальные науки. - 2017. - № 3 (75). - С. 378 -383.

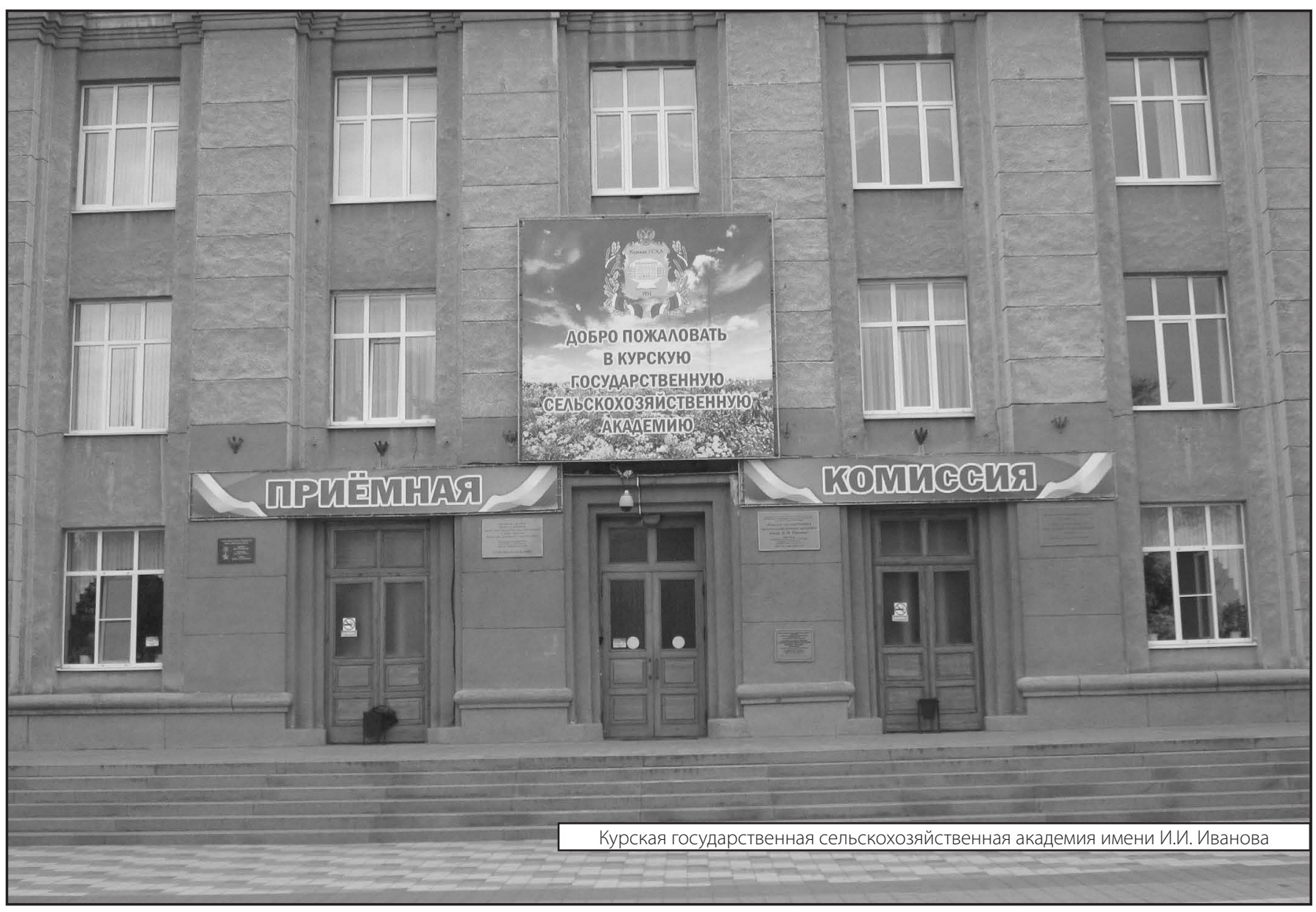

